\title{
Early results of robotically assisted mitral valve surgery: Analysis of the first 1000 cases
}

\author{
A. Marc Gillinov, MD, ${ }^{\mathrm{a}}$ Tomislav Mihaljevic, $\mathrm{MD},{ }^{\mathrm{a}}$ Hoda Javadikasgari, $\mathrm{MD},{ }^{\mathrm{a}}$ \\ Rakesh M. Suri, MD, DPhil, ${ }^{\mathrm{a}}$ Stephanie L. Mick, MD, ${ }^{\mathrm{a}}$ José L. Navia, MD, ${ }^{\mathrm{a}}$ Milind Y. Desai, MD,${ }^{\mathrm{b}}$ \\ Johannes Bonatti, MD, ${ }^{a}$ Mitra Khosravi, BS, ${ }^{a}$ Jay J. Idrees, MD, ${ }^{a}$ Ashley M. Lowry, MS, \\ Eugene H. Blackstone, MD, ${ }^{\mathrm{a}, \mathrm{c}}$ and Lars G. Svensson, $\mathrm{MD}, \mathrm{PhD}^{\mathrm{a}}$
}

\section{ABSTRACT}

Objective: The study objective was to assess the technical and process improvement and clinical outcomes of robotic mitral valve surgery by examining the first 1000 cases performed in a tertiary care center.

Methods: We reviewed the first 1000 patients (mean age, $56 \pm 10$ years) undergoing robotic primary mitral valve surgery, including concomitant procedures $(\mathrm{n}=185)$, from January 2006 to November 2013. Mitral valve disease cause was degenerative $(n=960,96 \%)$, endocarditis $(n=26,2.6 \%)$, rheumatic $(\mathrm{n}=10,1.0 \%)$, ischemic $(\mathrm{n}=3,0.3 \%)$, and fibroelastoma $(\mathrm{n}=1,0.1 \%)$. All procedures were performed via right chest access with femoral perfusion for cardiopulmonary bypass.

Results: Mitral valve repair was attempted in 997 patients ( 2 planned replacements and 1 resection of fibroelastoma), 992 (99.5\%) of whom underwent valve repair, and $5(0.5 \%)$ of whom underwent valve replacement. Intraoperative postrepair echocardiography showed that $99.7 \%$ of patients receiving repair (989/ 992) left the operating room with no or mild mitral regurgitation, and predischarge echocardiography showed that mitral regurgitation remained mild or less in $97.9 \%$ of patients $(915 / 935)$. There was 1 hospital death $(0.1 \%)$, and 14 patients $(1.4 \%)$ experienced a stroke; stroke risk declined from $2 \%$ in the first 500 patients to $0.8 \%$ in the second 500 patients. Over the course of the experience, myocardial ischemic and cardiopulmonary bypass times $(P<.0001)$, transfusion $(P=.003)$, and intensive care unit and postoperative lengths of stay $(P<.05)$ decreased.

Conclusions: Robotic mitral valve surgery is associated with a high likelihood of valve repair and low operative mortality and morbidity. The combination of algorithm-driven patient selection and increased experience enhanced clinical outcomes and procedural efficiency. (J Thorac Cardiovasc Surg 2018;155:82-91)

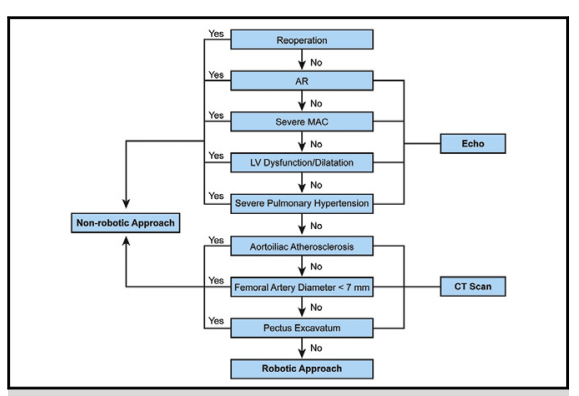

Algorithm to select candidates for robotically assisted mitral valve surgery.

\section{Central Message}

Robotically assisted mitral valve surgery provides successful, effective, and safe mitral valve repair, particularly in patients with leaflet prolapse.

\section{Perspective}

Use of an algorithm to guide patient selection is associated with safe robotically assisted mitral valve surgery. Better understanding of the outcomes of robotically assisted mitral valve repair may lead to greater adoption of the procedure.

See Editorial Commentaries page 92 and 94.

See Editorial page 77.
From the Departments of ${ }^{\mathrm{a}}$ Thoracic and Cardiovascular Surgery, ${ }^{\mathrm{b}}$ Cardiovascular Medicine, Heart and Vascular Institute, and ${ }^{\mathrm{c}}$ Quantitative Health Sciences, Research Institute, Cleveland Clinic, Cleveland, Ohio.

This study was supported in part by the Gus P. Karos Registry Fund; the David Whitmire Hearst Jr, Foundation; the Baxter Family Fund; the Judith Dion Pyle Endowed Chair in Heart Valve Research, held by A.M.G.; and the Drs Sidney and Becca Fleischer Heart and Vascular Education Chair, held by E.H.B.

Read at the 96th Annual Meeting of The American Association for Thoracic Surgery, Baltimore, Maryland, May 14-18, 2016.

Received for publication Oct 27, 2016; revisions received July 11, 2017; accepted for publication July 21, 2017; available ahead of print Sept 8, 2017.

Address for reprints: A. Marc Gillinov, MD, Department of Thoracic and Cardiovascular Surgery, Cleveland Clinic, 9500 Euclid Ave/Desk J4-1, Cleveland, OH 44195 (E-mail: gillinom@ccf.org).

$0022-5223 / \$ 36.00$

Copyright (c) 2017 by The American Association for Thoracic Surgery

http://dx.doi.org/10.1016/j.jtcvs.2017.07.037
Robotically assisted mitral valve surgery is the least invasive surgical approach to the mitral valve. Using a stereoscopic high-definition camera with 10 -fold magnification, a dynamic retractor, and a variety of wristed instruments, the surgeon has unparalleled visualization of and access

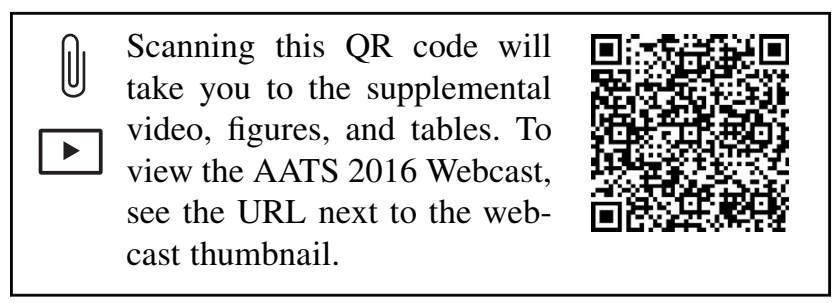




\section{Abbreviations and Acronyms \\ $\mathrm{AR}=$ aortic regurgitation \\ $\mathrm{CT}=$ computed tomography \\ $\mathrm{MR}=$ mitral regurgitation \\ PTFE $=$ polytetrafluoroethylene \\ TTE $=$ transthoracic echocardiography}

to the mitral valve. This technology enables surgeons to work through ports and small incisions on the right chest and to perform standard mitral valve procedures while sparing the patient a sternotomy. Other reported advantages for the patient include shorter postoperative stay, reduced need for blood transfusions, quicker return to full activity, and superior cosmesis. ${ }^{1-3}$

Despite reports documenting the efficacy and safety of robotically assisted mitral valve surgery, it has not become the standard of care for managing mitral valve disease. Concerns persist regarding prolonged operative time, quality of valve repair, and hospital resource use. ${ }^{4}$ After extensive training and preparation, our surgical team began to perform robotically assisted mitral valve surgery in 2006 . We report the results of our first 1000 consecutive robotic cases, emphasizing technical and process improvement initiatives undertaken during the course of this experience, early in-hospital safety, and residual mitral regurgitation (MR).

\section{PATIENTS AND METHODS \\ Patients}

From the first robotically assisted mitral valve surgery performed at Cleveland Clinic between January 2006 and November 2013, 1000 patients underwent primary robotically assisted mitral valve surgery. This represented $30 \%$ of 3307 patients undergoing primary isolated mitral valve surgery during that time. Patients' mean age was $56 \pm 10$ years (range, $18-83$ years), $77 \%$ were male, and $93 \%$ were in New York Heart Association functional class I/II (Table 1). All patients had severe MR according to standard integrated echocardiographic criteria ${ }^{5}$ except $2: 1$ with mitral stenosis and 1 with fibroelastoma. The majority of patients had degenerative mitral valve disease (Table 2). Among 960 patients with degenerative disease, $768(80 \%)$ had isolated posterior leaflet prolapse on transthoracic echocardiography (TTE), 166 (17\%) had bileaflet prolapse, and $24(2.5 \%)$ had isolated anterior leaflet prolapse.

These and other data presented in this article were based on routine prospective data collection for quality and research by the Heart and Vascular Institute's Clinical Investigations group and were approved for use in research by the Cleveland Clinic Institutional Review Board, with patient consent waived.

\section{Preoperative and Intraoperative Screening}

Our preoperative screening strategy starts with routine laboratory work and chest radiography. All patients undergo coronary angiography or computed tomography (CT) angiography, and a robotic approach is not used if coronary artery bypass grafting is required. Other preoperative screening imaging includes TTE and CT scanning of the chest, abdomen, and pelvis. Intraoperative screening includes femoral ultrasound.
TABLE 1. Patient characteristics $(n=1000)$

\begin{tabular}{|c|c|c|}
\hline Characteristic & $\mathbf{n}^{*}$ & No. $(\%)$ or Mean \pm SD \\
\hline \multicolumn{3}{|l|}{ Demographics } \\
\hline Age $(y)$ & 1000 & $56 \pm 10$ \\
\hline Male & 1000 & 770 (77) \\
\hline Body mass index $\left(\mathrm{kg} / \mathrm{m}^{2}\right)$ & 995 & $26 \pm 3.9$ \\
\hline \multicolumn{3}{|l|}{ Symptoms } \\
\hline NYHA functional class & 896 & \\
\hline I & & $470(52)$ \\
\hline II & & $359(40)$ \\
\hline III & & $65(7.3)$ \\
\hline IV & & $2(0.22)$ \\
\hline Ejection fraction $(\%)$ & 930 & $60 \pm 5.1$ \\
\hline \multicolumn{3}{|l|}{ Cardiac comorbidities } \\
\hline MR grade & 1000 & \\
\hline None & & $2(0.20)$ \\
\hline Moderate to severe & & $209(21)$ \\
\hline Severe & & 789 (79) \\
\hline Mitral stenosis & 742 & \\
\hline None & & 738 (99) \\
\hline Mild & & $2(0.27)$ \\
\hline Severe & & $2(0.27)$ \\
\hline Atrial fibrillation & 1000 & $89(8.9)$ \\
\hline Prior myocardial infarction & 1000 & $16(1.6)$ \\
\hline TR grade & 1000 & \\
\hline None & & $731(73)$ \\
\hline Mild & & 185 (19) \\
\hline Moderate & & $84(8.1)$ \\
\hline AR grade & 1000 & \\
\hline None & & 945 (94) \\
\hline Mild & & $45(4.5)$ \\
\hline Moderate & & $10(1.0)$ \\
\hline \multicolumn{3}{|l|}{ Noncardiac comorbidities } \\
\hline Carotid disease & 1000 & $35(3.5)$ \\
\hline Stroke & 1000 & $22(2.2)$ \\
\hline Peripheral arterial disease & 1000 & $12(1.2)$ \\
\hline Hypertension & 1000 & $411(41)$ \\
\hline Diabetes & 999 & $18(1.8)$ \\
\hline COPD & 1000 & $37(3.7)$ \\
\hline
\end{tabular}

$S D$, Standard deviation; NYHA, New York Heart Association; $M R$, mitral regurgitation; $T R$, tricuspid regurgitation; $A R$, aortic regurgitation; $C O P D$, chronic obstructive pulmonary disease. *Patients with data available.

Transthoracic echocardiography. Several features are examined to determine whether a robotic approach is appropriate:

1. Severity of mitral annular calcification: A robotic approach is not used for patients with moderately severe or severe mitral annular calcification because robotic instrumentation is not well suited to managing it.

2. Left ventricular function: Because robotic surgery generally requires a longer period of myocardial ischemia than other approaches, it is not used for patients with important left ventricular dysfunction.

3. Severity of aortic regurgitation (AR): Presence of greater than mild AR complicates myocardial protection and can lead to ventricular distension after release of the aortic clamp. Therefore, we do not use the robotic approach in these patients.

Computed tomography scan. CT scanning of the chest, abdomen, and pelvis is used to evaluate the feasibility and safety of peripheral perfusion 
TABLE 2. Mitral valve cause and pathology

\begin{tabular}{lcc}
\hline \multicolumn{1}{c}{ Variable } & \multicolumn{1}{c}{$\mathbf{n}^{*}$} & No. $(\%)$ \\
\hline Cause of mitral valve disease & $1000(100)$ & \\
Degenerative & & $960(96)$ \\
Rheumatic & & $10(1.0)$ \\
Ischemic & $3(0.30)$ \\
Endocarditis & $26(2.6)$ \\
Fibroelastoma & $1(0.10)$ \\
Pathology of mitral valve leaflets & $330(33)$ & \\
Anterior & & \\
Normal & & $5(1.5)$ \\
Prolapse & $307(93)$ \\
Tethering/restriction & $5(1.5)$ \\
Other & & $13(3.9)$ \\
Posterior & & \\
Normal & & $4(0.41)$ \\
Prolapse & & $19(1.9)$ \\
Tethering/restriction & & $5(0.52)$ \\
Other & & \\
\hline
\end{tabular}

*Patients with data available.

for cardiopulmonary bypass. A femoral artery less than $7 \mathrm{~mm}$ in diameter and important aortoiliac atherosclerosis constitute relative contraindications to robotic surgery. For the first 500 cases, CT scanning was obtained sporadically. Recognizing a $2 \%$ occurrence of perioperative stroke, we thereafter instituted a formal policy of obtaining such scans in all patients. Specific features of interest on the scans include presence or absence of atherosclerotic disease, femoral vessel size, unexpected vascular anatomy (eg, discontinuous inferior vena cava), and previously unrecognized pathology (eg, iliac dissection after cardiac catheterization and aortic coarctation). ${ }^{6}$

Screening algorithm. We incorporated imaging studies after the first 500 cases into an algorithm to facilitate selection of candidates for robotically assisted surgery (Central Figure). Table 3 lists both strong and relative contraindications to robotic mitral valve surgery in our center. Of the 1000 patients, $18(1.8 \%)$ did not follow the screening rules, including 17 with greater than mild AR and 1 with moderate-to-severe preoperative left ventricular systolic dysfunction. Eleven of the 18 were among the most recent 500 cases. The screening algorithm is used to determine the approach in conjunction with the surgeon's judgment and the patient's desires.

\section{Surgical Technique}

For this study, the surgical approach was considered robotic if the robot was actually placed into the surgical field. Mitral valve repair was attempted in 997 patients $(99.7 \%)$, with $2(0.2 \%)$ planned replacements and $1(0.1 \%)$ resection of fibroelastoma. The surgical approach for patients undergoing robotic mitral valve surgery has been described (Video 1). ${ }^{3,7}$ Briefly, access ports are placed through the right chest, including a 40-mm minithoracotomy working port with a soft tissue retractor when a Chitwood clamp was used for aortic occlusion, and a 15- to 20-mm working port when an intra-aortic balloon was used. Right internal jugular and femoral veins are cannulated for cardiopulmonary bypass. The ascending aorta is occluded by a Chitwood transthoracic clamp $(\mathrm{n}=737,74 \%)$ or an intra-aortic balloon $(\mathrm{n}=263$, $26 \%$ ). The choice rested on surgeon preference and comfort level. The heart is then arrested with $1 \mathrm{~L}$ of Buckberg cardioplegia readministered every 15 to 20 minutes or with a single dose of del Nido cardioplegia.

Mitral valve repair. Standard robotically assisted repair techniques ${ }^{8}$ were used in all cases. Techniques used to correct posterior leaflet prolapse included triangular or quadrangular leaflet resection (74\%), sliding repair $(27 \%))^{9}$ folding valvuloplasty $(6.5 \%),{ }^{10,11}$ and insertion of polytetrafluoroethylene (PTFE) chords (24\%) (Table 4). Anterior leaflet prolapse was treated by inserting PTFE chords $(80 \%)$ and chordal transfer $(8.2 \%)$. For bileaflet repair $(16 \%)$, other than for repair of posterior and anterior leaflets, an edge-to-edge Alfieri stitch (8.8\%) and commissuroplasty $(69 \%)$ were used. All valve repairs included insertion of a flexible standard-length annuloplasty band (Cosgrove-Edwards Annuloplasty System, Edwards Lifesciences, Irvine, Calif; or Duran band, Medtronic, Minneapolis, Minn ${ }^{12}$ ) with 2-0 polyester suture.

Tricuspid valve repair. A vertical right atriotomy was made, and repair was performed using an annuloplasty band sewn into place with interrupted 2-0 polyester suture.

Atrial fibrillation procedure. The left atrial appendage was routinely closed as part of the CryoMaze operation in a 2-layer fashion

TABLE 3. Strong and relative contraindications for robotic mitral valve repair at Cleveland Clinic

\begin{tabular}{ll}
\hline \multicolumn{1}{c}{ Strong contraindications } & \multicolumn{1}{c}{ Relative contraindications } \\
\hline Previous right thoracotomy & Previous sternotomy \\
Significant aortic root/ascending aortic dilatation & Mild aortic stenosis or regurgitation \\
\hline Moderate or severe aortic valve regurgitation & Reduced left ventricular function $(\mathrm{EF}<50 \%)$ \\
\hline Fixed pulmonary hypertension $(>60 \mathrm{~mm} \mathrm{Hg})$ & Variable pulmonary hypertension $(>50 \mathrm{~mm} \mathrm{Hg})$ \\
\hline Right ventricular dysfunction & Limited peripheral arterial disease \\
Severe generalized peripheral arterial disease & Chest deformity (pectus/scoliosis) \\
\hline Calcification of the aortic root/ascending aorta & Asymptomatic, mild coronary disease \\
Mitral annular calcification & Moderate pulmonary dysfunction \\
\hline Myocardial infarction or ischemia $<30 \mathrm{~d}$ & Asymptomatic cerebrovascular disease \\
Coronary artery disease requiring CABG & \\
\hline Severe pulmonary dysfunction & \\
Symptomatic cerebrovascular disease or stroke $<30 \mathrm{~d}$ & \\
\hline Severe liver dysfunction & \\
Significant bleeding disorder & \\
\hline$E F$ Ejection fraction; $C A B G$, coronary artery bypass grafting. & \\
\hline
\end{tabular}

$E F$, Ejection fraction; $C A B G$, coronary artery bypass grafting. 


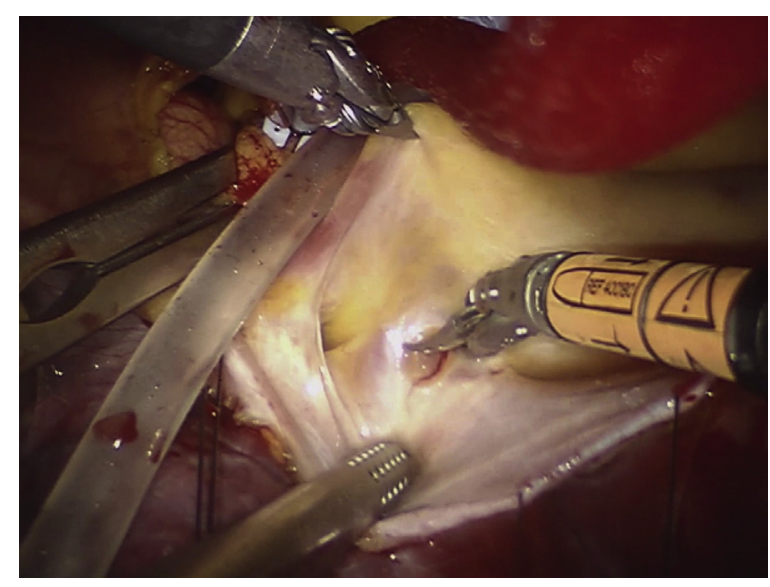

VIDEO 1. Robotic mitral valve repair. Video available at: http://www. jtcvsonline.org/article/S0022-5223(17)31581-7/fulltext.

using 3-0 PTFE suture. Cryoablation was performed with a box lesion around the pulmonary veins. We then connected this lesion to the mitral valve annulus.

Adjunct pharmacologic therapy. When there was no contraindication, we administered perioperative beta-blockers to decrease the risk of atrial fibrillation, as well as postoperative aspirin. Warfarin was prescribed postoperatively for patients with recurrent or persistent atrial fibrillation.

\section{Outcomes}

Technical performance and residual mitral regurgita-

tion. Technical performance of surgical approaches was assessed by evaluating operative variables (intraoperative transesophageal echocardiography and cardiopulmonary bypass and myocardial ischemic times). Quality of mitral valve repair was assessed by residual MR on routine predischarge TTE.

Safety. Safety was assessed by in-hospital mortality and morbidity as defined for the Society of Thoracic Surgeons National Cardiac Database (http://www.sts.org/sites/default/files/documents/STSAdultCVData SpecificationsV2_81.pdf).

\section{Data Analysis and Presentation}

All analyses were performed using SAS statistical software (SAS version 9.2; SAS Institute, Inc, Cary, NC) and R software version 3.2.2. ${ }^{13}$

Continuous variables are summarized as mean \pm standard deviation, and statistical significance of trends with experience was estimated using a linear regression model for a simple transformation of patient sequence number. Categoric variables are summarized as frequencies and percentages, and statistical significance trends with experience were estimated using a logistic regression model for a simple transformation of patient sequence number. Trends are displayed using a smoothing spline (R statistical software). ${ }^{14}$

\section{RESULTS}

\section{Technical Performance}

Cardiopulmonary bypass time decreased slightly after approximately 200 cases and then remained level at approximately 120 minutes on average (Figure 1, A). Average myocardial ischemic time decreased from 110 minutes to 80 minutes over the first 200 cases and remained constant thereafter (Figure 1, B). Although all patients had a flexible
TABLE 4. Operative details

\begin{tabular}{|c|c|c|}
\hline Detail & $\mathbf{n}^{*}$ & No. $(\%)$ \\
\hline \multicolumn{3}{|l|}{ Type of mitral valve repair } \\
\hline Posterior leaflet only & 998 & $782(78)$ \\
\hline Resection & 782 & $603(77)$ \\
\hline Triangular & 603 & $385(64)$ \\
\hline Folding valvuloplasty & 385 & $56(15)$ \\
\hline Quadrangular & 603 & $218(36)$ \\
\hline Sliding repair & 218 & $218(100)$ \\
\hline PTFE artificial chordae & 782 & $174(22)$ \\
\hline Anterior leaflet only & 998 & $27(2.7)$ \\
\hline PTFE artificial chordae & 27 & $19(70)$ \\
\hline Bileaflet & 998 & $159(16)$ \\
\hline Posterior leaflet & 159 & $107(67)$ \\
\hline Resection & 107 & $54(50)$ \\
\hline Triangular & 54 & $29(54)$ \\
\hline Folding valvuloplasty & 29 & $2(6.9)$ \\
\hline Quadrangular & 54 & $25(46)$ \\
\hline Sliding repair & 25 & $25(100)$ \\
\hline PTFE artificial chordae & 107 & $43(40)$ \\
\hline Anterior leaflet & 159 & $58(36)$ \\
\hline PTFE artificial chordae & 58 & $49(84)$ \\
\hline Chordal transfer & 58 & $7(12)$ \\
\hline Commissuroplasty & 159 & $109(69)$ \\
\hline Anterolateral & 109 & $49(45)$ \\
\hline Posteromedial & 109 & $60(55)$ \\
\hline Alfieri stitch & 159 & $14(8.8)$ \\
\hline Annuloplasty & 998 & $986(99)$ \\
\hline Annuloplasty only & 986 & $30(3.0)$ \\
\hline \multicolumn{3}{|l|}{ Concomitant procedures } \\
\hline Ablation for atrial fibrillation & 1000 & $72(7.2)$ \\
\hline PFO/ASD closure & 1000 & $90(9.0)$ \\
\hline Tricuspid valve repair & 998 & $2(0.20)$ \\
\hline
\end{tabular}

PTFE, Polytetrafluoroethylene; $P F O / A S D$, patent foramen ovale/atrial septal defect. *Patients with applicable data.

annuloplasty band inserted as part of the repair, other components of mitral valve surgical technique complexity increased as sequence number increased (Figure E1).

Of the 997 patients with intent to repair, 992 (99.5\%) underwent mitral valve repair and $5(0.5 \%)$ were converted to replacement. Among the 1000 patients, 20 (2\%) were converted to full or partial sternotomy and $23(2.3 \%)$ were converted to minithoracotomy. Indications for conversion included bleeding $(\mathrm{n}=6)$, inadequate exposure $(\mathrm{n}=5)$, patient anatomy $(\mathrm{n}=9)$, arrhythmia $(\mathrm{n}=1)$, unsatisfactory repair $(\mathrm{n}=14)$, ischemia $(\mathrm{n}=3)$, inadequate arrest $(\mathrm{n}=3)$, aortic dissection $(\mathrm{n}=1)$, and $\mathrm{AR}(\mathrm{n}=1)$. The number of conversions to full or partial sternotomy decreased over time (Figure 2). 

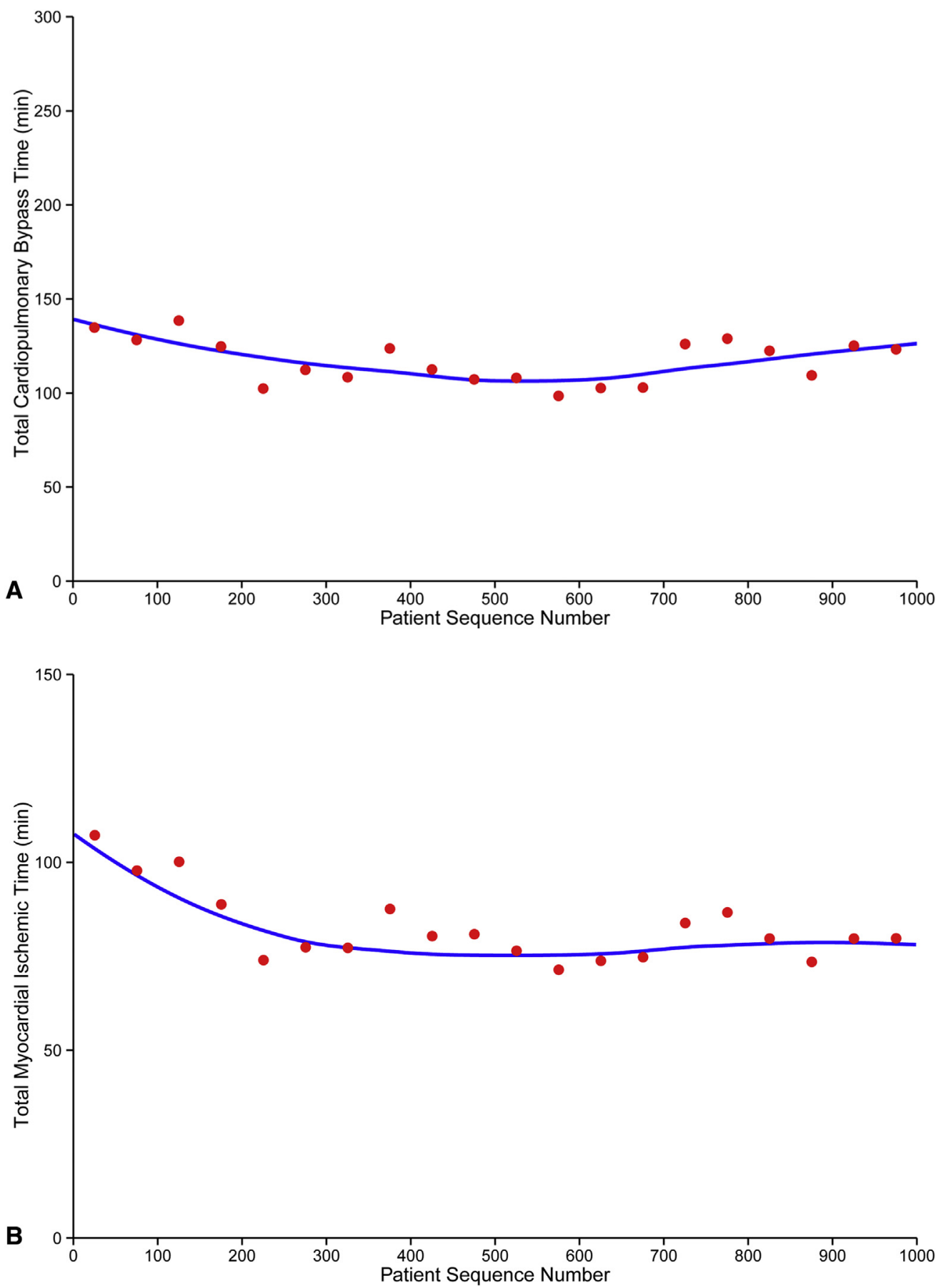

FIGURE 1. Operative times across patient sequence number. Solid lines represent the smoothing spline curve, and filled circles represent the mean for every 50 patients. A, Cardiopulmonary bypass time. B, Myocardial ischemic time, which plateaued after approximately 200 cases.

\section{Safety}

Nine patients had intra-aortic complications or difficulties, including balloon rupture $(\mathrm{n}=5)$, pressure loss $(\mathrm{n}=1)$, malpositioning with low pressure in both arms $(\mathrm{n}=1)$, inadequate cardiac arrest $(\mathrm{n}=1)$, and coiling of the catheter $(\mathrm{n}=1)$. Seven patients experienced myocardial ischemia, which was treated empirically. In 6 cases, the surgeon considered the possibility of impingement on the circumflex coronary artery; this prompted revision of the annuloplasty and resulted in resolution of ischemia in all cases ( 2 patients were converted to a minithoracotomy; the others were treated robotically). In 1 case, the surgeon 


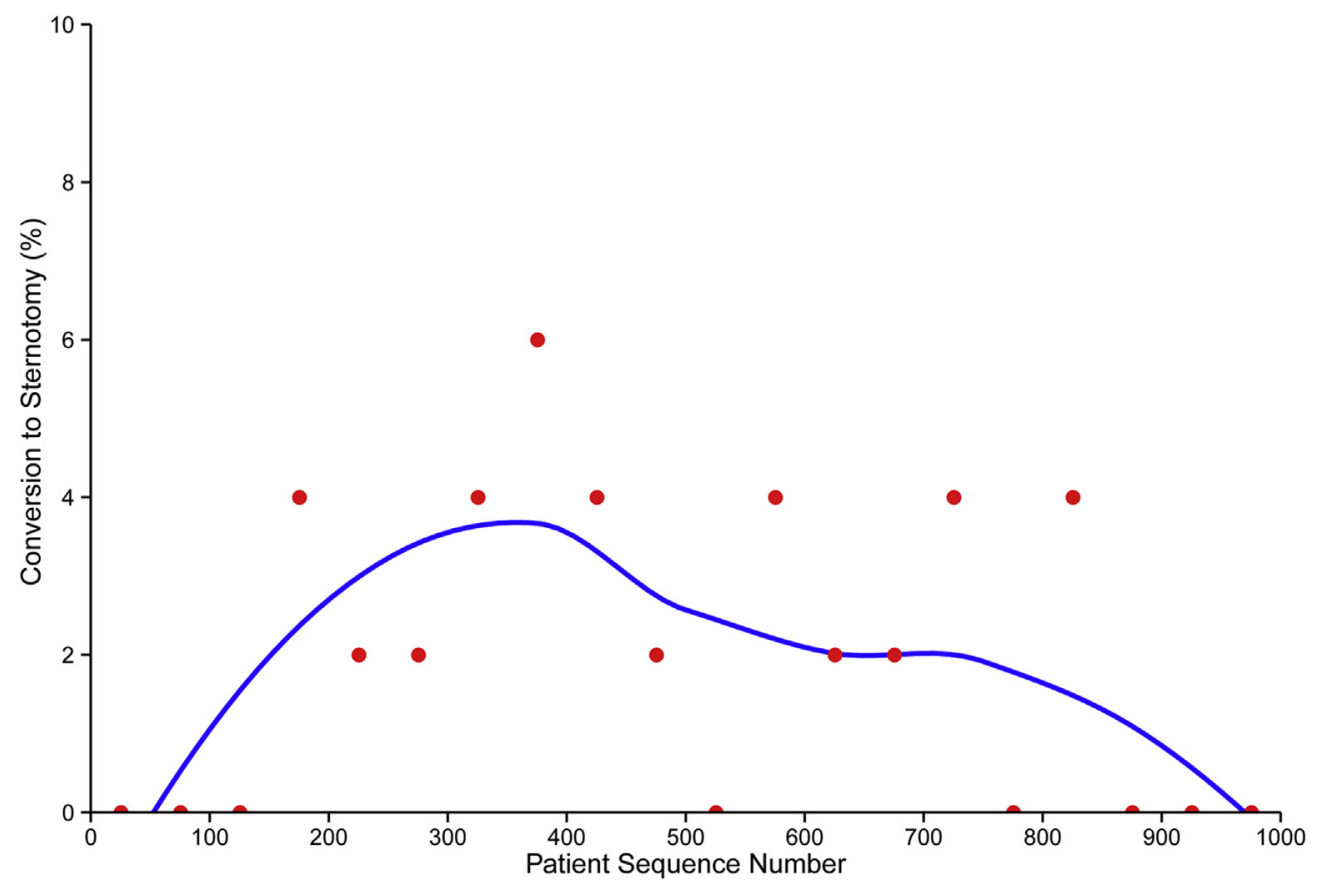

FIGURE 2. Conversion from robotic to complete or partial sternotomy across patient sequence number. Lines represent the smoothing spline curve, and symbols represent the percentage for every 50 patients.

performed a sternotomy and placed a bypass graft to the right coronary artery, which resolved the ischemia.

There was a single operative death $(0.1 \%)$, due to right atrial wire perforation and bleeding (Table 5). There was no femoral artery or vein injury requiring vascular surgical intervention in this series. Fourteen patients $(1.4 \%)$ had a stroke, confirmed by both clinical examination and imaging (CT scan or magnetic resonance imaging). The source of stroke was embolic in 8 patients $(57 \%)$, hypoperfusion in 2 patients $(14 \%)$, and indeterminate in 4 patients $(29 \%)$. By hospital discharge, 6 patients demonstrated complete neurologic recovery. Stroke occurred in $10(2 \%)$ of the first 500 patients in whom preoperative abdominal and pelvic

TABLE 5. Postoperative in-hospital complications $(n=1000)$

\begin{tabular}{lc}
\hline \multicolumn{1}{c}{ Variable } & No. $(\%)$ \\
\hline Death & $1(0.10)$ \\
Stroke & $14(1.4)$ \\
Surgical site infection & $0(0)$ \\
New-onset atrial fibrillation* & $189(21)$ \\
Reoperation for bleeding & $25(2.5)$ \\
Prolonged ventilation $(>24 \mathrm{~h})$ & $21(2.1)$ \\
Renal failure & $1(0.10)$ \\
Aortic dissection & $1(0.10)$ \\
ICD implantation & $4(0.40)$ \\
\hline
\end{tabular}

$I C D$, Implantable cardioverter-defibrillator. $*_{\mathrm{n}}=911$. Patients with preoperative atrial fibrillation were excluded from denominator.
CT scans were not routinely available and $4(0.8 \%)$ of the second 500 patients (Figure 3, A, Table E1; $P$ [trend] $=.2$ ) who did not have risk factors for stroke.

Three patients $(0.3 \%)$ had phrenic nerve palsy, which resolved by 6 -month follow-up in 1 patient. There were no surgical site infections (Table 5). Twenty-five patients $(2.5 \%)$ underwent reoperation for bleeding, performed through the minithoracotomy with video assistance. A single patient required a sternotomy because of hemodynamic instability; in that patient, the bleeding arose from the right atrium. A total of 189 patients $(21 \%)$ experienced new-onset atrial fibrillation. Over the experience, transfusions (Figure 3, B, Table E1; P[trend] $=.003$ ) and intensive care unit length of stay declined (Figure 3, $C$, Table E1; P[trend] $=.05$ ), as did postoperative length of stay (Figure $3, D$, Table E1; $P$ $[$ trend $]=.04)$.

\section{Residual Mitral Regurgitation}

Intraoperative postrepair echocardiography confirmed that $99.7 \%(n=989 / 992)$ of patients who received repair left the operating room with MR graded as none or mild, and predischarge echocardiography (Table E2) confirmed no MR in 832 of 935 patients $(89 \%)$ and mild MR in 83 patients $(8.9 \%)$, for a total of 915 of 935 patients $(97.9 \%)$ with no or mild MR.

Mitral valve reoperation before hospital discharge was performed in 5 patients $(0.5 \%)$ as a result of systolic 

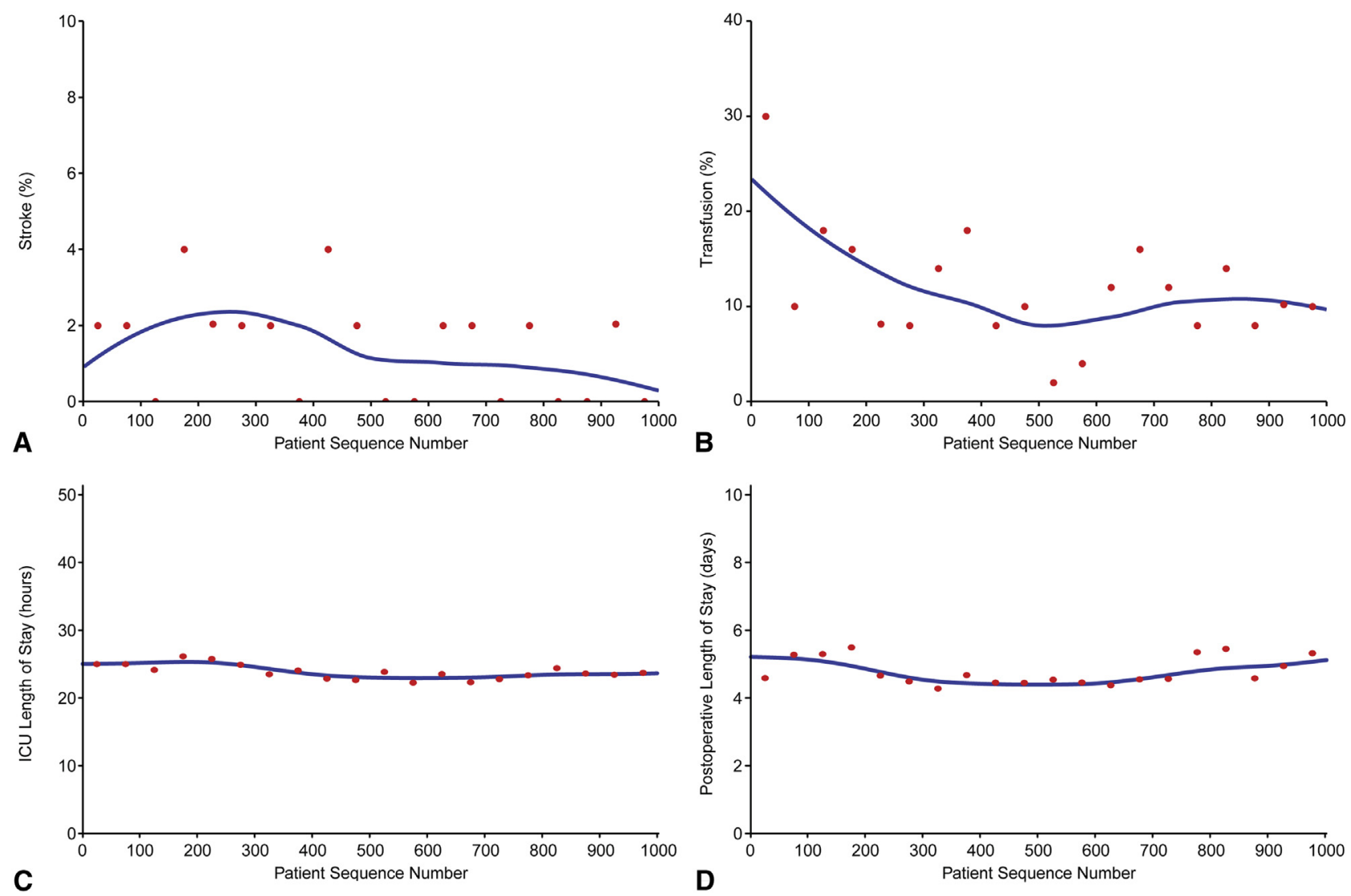

FIGURE 3. Clinical outcomes according to patient sequence number. A, Stroke. Format is as in Figure 2. B, Transfusion. Format is as in Figure 2. C, Median intensive care unit length of stay. Solid line represents the smoothing spline curve for the median, and filled circles represent the median for every 50 patients. D, Median postoperative length of stay. Solid line represents the smoothing spline curve for the median, and filled circles represent the median for every 50 patients. $I C U$, Intensive care unit.

anterior motion and residual or recurrent MR. One of these reoperations was performed with robotic assistance.

\section{DISCUSSION}

\section{Key Findings}

This study demonstrates that algorithm-driven robotic surgery enables mitral valve repair with high early procedural success and low risks of morbidity and mortality. Although initial aortic clamp and cardiopulmonary bypass times, transfusions, and occurrence of stroke were higher, procedural efficiency and safety improved with increasing experience and application of algorithm-driven patient selection. Technical and process improvement and early inhospital safety were achieved in part by strategically introducing robotically assisted mitral valve surgery by a single surgeon highly experienced in mitral repair. Subsequently, another experienced mitral valve surgeon was introduced, and recently, a third. Improvement was also driven by a conservative approach that led to the screening algorithm presented in Figure E2 and the Central Figure and a liberal approach to conversion from robotic to conventional incisions. This permitted surgeons to progressively gain experience without compromising procedural success, effectiveness, or patient safety.

\section{Current Guidelines}

Robotically assisted mitral valve surgery was introduced in the late 1990s to enhance mitral valve operations by improving technical precision and decreasing procedural invasiveness. The combination of highresolution 3-dimensional imaging and maneuverability of endoscopic instruments facilitates complete mitral valve repair for nearly all patients with degenerative disease. American College of Cardiology/American Heart Association guidelines provide a Class IIb recommendation: "...MV repair is reasonable in asymptomatic patients with chronic severe primary MR (stage C1) with preserved left ventricular function (left ventricular ejection fraction $>60 \%$ and left ventricular end-systolic diameter $<40 \mathrm{~mm}$ ) in whom the likelihood of a successful and durable repair without residual MR is $>95 \%$ with an expected mortality rate of $<1 \% \ldots . "{ }^{15}$ Robotically assisted mitral valve repair satisfies these criteria and therefore represents a particularly appealing approach for 
asymptomatic patients with severe MR caused by degenerative disease.

Despite favorable results with robotically assisted mitral valve surgery, perceived and real concerns about procedural complexity and cost, as well as challenging patient characteristics (eg, mitral annular calcification and aortoiliac atherosclerosis), have limited its acceptance. ${ }^{16-18}$ Our algorithm (Table 3, Figure E2, and Central Figure) directs patients with unfavorable features to a nonrobotic approach, which generally provides a safer option for mitral valve surgery. Although it is possible to work around each of these limitations and still use the surgical robot, we believe that a conservative approach is most appropriate to optimize patient outcomes.

\section{Technical Performance}

Over the course of this 1000-patient experience, operative technique evolved, facilitating valve repair and reducing myocardial ischemic time. We believe that surgeon experience and simplified techniques to correct leaflet prolapse (inserting artificial chords rather than chordal transfer and triangular resection rather than extensive resection), coupled with a running suture technique to place the annuloplasty band, reduced aortic clamp times. ${ }^{12,19}$ However, the long-term results of a running suture technique for annuloplasty insertion have not been documented.

Streamlined techniques and new instrumentation, combined with increased surgeon experience and better understanding of patient candidacy, improved results over time. Conversion to partial and complete sternotomy was higher than expected. However, with increased experience, in the last 200 cases it declined to $1 \%$.

\section{Residual Mitral Regurgitation}

Mitral valve repair was achieved in $99.5 \%$ of patients for whom it was intended, and $97.9 \%$ of these had no or only mild MR at discharge. These excellent results in a large series, similar to those of others, ${ }^{17,18,20,21}$ emphasize that the results are reproducible. Although our study reports only inhospital outcomes, others performing robotically assisted mitral valve repair have documented 5-year survival, freedom from recurrent MR, and freedom from reoperation of $99.5 \%, 94.6 \%$, and $97.7 \%$, respectively. ${ }^{17}$ Studies of long-term results of robotically assisted mitral valve repair demonstrate that survival and durability are similar to those obtained with nonrobotic approaches. $3,17,18$

\section{Safety}

Safety is contingent on conservative identification of appropriate candidates, procedural technique, and willingness to convert without hesitation from the robotic approach to a conventional approach if it appears to compromise valve repair or risk adverse outcomes. Several studies, including our own, demonstrate the safety of robotically assisted mitral valve surgery. $3,17,18,20,21$ Compared with nonrobotic approaches, it has been associated with lower in-hospital mortality, less blood loss, fewer incisional infections, shorter postoperative lengths of stay, more rapid return to normal activity, and superior cosmesis. ${ }^{3,22-24}$ In our previous study of 261 patients undergoing robotically assisted mitral valve repair of degenerative posterior leaflet disease, quality of valve repair was similar in propensity-matched cohorts to that performed through a full sternotomy, partial sternotomy, or anterior thoracotomy, but less postoperative atrial fibrillation and fewer pleural effusions contributed to shorter postoperative stays. ${ }^{3}$

Retrograde femoral perfusion and the attendant risk of stroke remain an important concern. A recent report using the Society of Thoracic Surgeons' database documented 2fold higher occurrence of neurologic complications with less-invasive mitral valve surgery that included femoral artery perfusion. ${ }^{25}$ However, others contend there is no convincing evidence that retrograde perfusion per se during less-invasive mitral valve surgery increases the risk of stroke. ${ }^{26}$ We believe that retrograde embolization of atheromatous material, and embolization of air and debris from the left atrium, are the most likely causes; placing a clamp on an atherosclerotic aorta is another potential source of emboli. Preoperative CT scanning identifies patients at risk, enabling use of safer perfusion strategies. The latter might include axillary artery cannulation for cardiopulmonary bypass. ${ }^{27}$

\section{Study Limitations}

This study has limitations inherent to all single-institution clinical studies. We did not assess cost or resource use; however, we and others have addressed those aspects of robotic mitral surgery in previous reports. ${ }^{13,28}$ Stroke remains an important concern. This study traces the evolution of robotic mitral surgery at our institution and thus includes several different surgical techniques as these evolved.

\section{CONCLUSIONS}

Successful and safe mitral valve repair is achievable with a variety of incisional approaches, including full sternotomy, partial sternotomy, right thoracotomy, and robotically assisted right chest approaches. ${ }^{3}$ In all cases, the surgeon's skill and experience, combined with algorithm-driven patient selection, high volume, and an exceptional care team, dictate the ultimate result. Robotically assisted mitral valve repair is an effective and safe approach for correcting MR, with low operative mortality and morbidity and approximately $100 \%$ successful valve repair. Results improve with experience, and algorithm-driven patient selection further enhances procedural efficiency and clinical outcomes. Robotically assisted mitral valve surgery sets a standard for comparison with emerging percutaneous mitral valve interventions. 


\section{Webcast}

You can watch a Webcast of this AATS meeting presentation by going to: http://webcast.aats.org/2016/Video/Wednesday/ 05-18-16_Ballroom_I_0741_Gillinov-800.mp4.

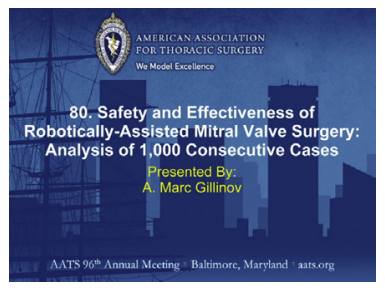

\section{Conflict of Interest Statement}

A.M.G. is a consultant for CryoCath Technologies, Edwards Lifesciences, Medtronic, St Jude Medical, Abbott Laboratories, and Atricure; and receives research funding from St Jude Medical and Tendyne. J.L.N. discloses a financial relationship with Edwards Lifesciences, St Jude Medical, and MAQUET, and is a member of the scientific board for NaviGate Cardiac Structures. L.G.S. is an unpaid member of the executive committee for PARTNER trials I and II and an unpaid member of the executive committee of the COMMENCE trial, sponsored by Edwards Lifesciences. All other authors have nothing to disclose with regard to commercial support.

\section{References}

1. Mohr FW, Falk V, Diegeler A, Walther T, Gummert JF, Bucerius J, et al. Computer-enhanced "robotic" cardiac surgery: experience in 148 patients. J Thorac Cardiovasc Surg. 2001;121:842-53.

2. Chitwood WR Jr, Rodriguez E, Chu MW, Hassan A, Ferguson TB, Vos PW, et al Robotic mitral valve repairs in 300 patients: a single-center experience. J Thorac Cardiovasc Surg. 2008;136:436-41.

3. Mihaljevic T, Jarrett CM, Gillinov AM, Williams SJ, DeVilliers PA, Stewart WJ, et al. Robotic repair of posterior mitral valve prolapse versus conventional approaches: potential realized. J Thorac Cardiovasc Surg. 2011;141:72-80.

4. Diodato MD Jr, Damiano RJ Jr. Robotic cardiac surgery: overview. Surg Clin North Am. 2003;83:1351-67. ix.

5. Zoghbi WA, Enriquez-Sarano M, Foster E, Grayburn PA, Kraft CD, Levine RA, et al. Recommendations for evaluation of the severity of native valvular regurgitation with two-dimensional and Doppler echocardiography. J Am Soc Echocardiogr. 2003;16:777-802.

6. Moodley S, Schoenhagen P, Gillinov AM, Mihaljevic T, Flamm SD, Griffin BP, et al. Preoperative multidetector computed tomography angiography for planning of minimally invasive robotic mitral valve surgery: impact on decision making. $J$ Thorac Cardiovasc Surg. 2013;146:262-8.e1.

7. Suri RM, Javadikasgari H, Mihaljevic T, Mick S, Gillinov AM. Don't miss the obvious: the dangers of lateral pericardial defects. J Thorac Cardiovasc Surg. 2016;152:e83-4.

8. Mihaljevic T, Pattakos G, Gillinov AM, Bajwa G, Planinc M, Williams SJ, et al. Robotic posterior mitral leaflet repair: neochordal versus resectional techniques. Ann Thorac Surg. 2013;95:787-94.

9. Gillinov AM, Cosgrove DM. Modified sliding leaflet technique for repair of the mitral valve. Ann Thorac Surg. 1999;68:2356-7.

10. Mihaljevic T, Blackstone EH, Lytle BW. Folding valvuloplasty without leaflet resection: simplified method for mitral valve repair. Ann Thorac Surg. 2006;82:e46-8.

11. Suri RM, Burkhart HM, Schaff HV. A novel method of leaflet reconstruction after triangular resection for posterior mitral valve prolapse. Ann Thorac Surg. 2010; 89:e53-6.

12. Mihaljevic T, Jarrett CM, Gillinov AM, Blackstone EH. A novel running annuloplasty suture technique for robotically assisted mitral valve repair. $J$ Thorac Cardiovasc Surg. 2010;139:1343-4.
13. Mihaljevic T, Koprivanac M, Kelava M, Goodman A, Jarrett C, Williams SJ, et al. Value of robotically assisted surgery for mitral valve disease. JAMA Surg. 2014; 149:679-86.

14. Ripley BD, Maechler MR. Implementation: fit a smoothing spline. Available at: http://stat.ethz.ch/R-manual/R-patched/library/stats/html/smooth.spline.html. Accessed July 15, 2006.

15. Nishimura RA, Otto CM, Bonow RO, Carabello BA, Erwin JP III, Guyton RA, et al. 2014 AHA/ACC guideline for the management of patients with valvular heart disease: a report of the American College of Cardiology/American Heart Association Task Force on Practice Guidelines. J Am Coll Cardiol. 2014;63:e57-185.

16. Suri RM, Dearani JA, Mihaljevic TM, Chitwood WR, Murphy DA, Trento A, et al. Mitral valve repair using robotic technology: safe, effective, and durable. J Thorac Cardiovasc Surg. 2016;151:1450-4.

17. Suri RM, Taggarse A, Burkhart HM, Daly RC, Mauermann W, Nishimura RA, et al. Robotic mitral valve repair for simple and complex degenerative disease: midterm clinical and echocardiographic quality outcomes. Circulation. 2015;132:1961-8.

18. Murphy DA, Moss E, Binongo J, Miller JS, Macheers SK, Sarin EL, et al. The expanding role of endoscopic robotics in mitral valve surgery: 1,257 consecutive procedures. Ann Thorac Surg. 2015;100:1675-82.

19. George KM, Mihaljevic T, Gillinov AM. Triangular resection for posterior mitral prolapse: rationale for a simpler repair. J Heart Valve Dis. 2009;18:119-21.

20. Ramzy D, Trento A, Cheng W, De Robertis MA, Mirocha J, Ruzza A, et al. Three hundred robotic-assisted mitral valve repairs: the Cedars-Sinai experience. $J$ Thorac Cardiovasc Surg. 2014;147:228-35.

21. Nifong LW, Rodriguez E, Chitwood WR Jr. 540 consecutive robotic mitral valve repairs including concomitant atrial fibrillation cryoablation. Ann Thorac Surg. 2012;94:38-43.

22. Suri RM, Burkhart HM, Daly RC, Dearani JA, Park SJ, Sundt TM III, et al. Robotic mitral valve repair for all prolapse subsets using techniques identical to open valvuloplasty: establishing the benchmark against which percutaneous interventions should be judged. J Thorac Cardiovasc Surg. 2011;142:970-9.

23. Paul S, Isaacs AJ, Jalbert J, Osakwe NC, Salemi A, Girardi LN, et al. A population-based analysis of robotic-assisted mitral valve repair. Ann Thorac Surg. 2015;99:1546-53.

24. Suri RM, Antiel RM, Burkhart HM, Huebner M, Li Z, Eton DT, et al. Quality of life after early mitral valve repair using conventional and robotic approaches. Ann Thorac Surg. 2012;93:761-9.

25. Gammie JS, Zhao Y, Peterson ED, O'Brien SM, Rankin JS, Griffith BP. J. Maxwell Chamberlain Memorial Paper for adult cardiac surgery. Less-invasive mitral valve operations: trends and outcomes from the Society of Thoracic Surgeons Adult Cardiac Surgery Database. Ann Thorac Surg. 2010;90:1401-8. 1410.e1; discussion 1408-10.

26. Modi P, Chitwood WR Jr. Retrograde femoral arterial perfusion and stroke risk during minimally invasive mitral valve surgery: is there cause for concern? Ann Cardiothorac Surg. 2013;2:E1.

27. Sabik JF, Lytle BW, McCarthy PM, Cosgrove DM. Axillary artery: an alternative site of arterial cannulation for patients with extensive aortic and peripheral vascular disease. J Thorac Cardiovasc Surg. 1995;109:885-91.

28. Suri RM, Thompson JE, Burkhart HM, Huebner M, Borah BJ, Li Z, et al. Improving affordability through innovation in the surgical treatment of mitral valve disease. Mayo Clin Proc. 2013;88:1075-84.

Key Words: cardiac surgery, heart valve repair, heart valve replacement, outcomes

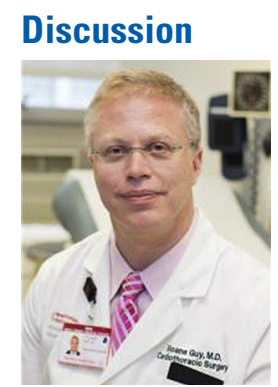

Dr T. S. Guy (New York, NY). Dr Gillinov, you and your colleagues are to be congratulated for this report, which represents one of the largest series of robotic mitral valve cases in the country.

I have a few questions for you. My first is, what was the primary driving motivation behind you and your colleagues at the Cleveland Clinic starting the robotic mitral valve program 
in the first place? After this large experience, have your perspectives changed on the relative value of robotics versus other approaches, such as sternotomy or port access?

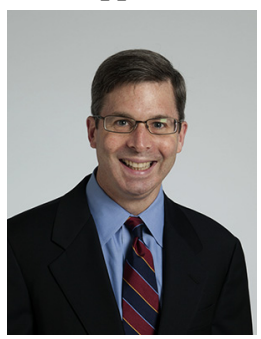

Dr Gillinov (Cleveland, Ohio). First, I should give credit to Tom Mihaljevic, because he was the first surgeon to perform robotic mitral valve surgery at Cleveland Clinic. He deserves a great deal of credit for getting this going.

The main reason that we started the robotic program was to be able to offer a broad range of options to the person who has mitral valve disease. Rather than a one size fits all approach, we wanted to be able to look at each patient and determine in our hands what will be best: robotic, right thoracotomy, partial sternotomy, or full sternotomy. Our goal was to be able to tailor the mitral operation to fit the patient.

Dr Guy. So if robotic approaches are as beneficial as your report would suggest that they are, why be so restrictive in whom you perform the procedure? For instance, reasonable alternative cannulation strategies exist for femoral arteries less than $7 \mathrm{~mm}$. You mentioned aortoiliac disease as a contraindication. Axillary cannulation is one option for these patients. Also, any mitral valve patients with mitral valve disease have pulmonary hypertension, need a replacement, have depressed left ventricular function, and have had prior cardiac surgery and pathologies other than prolapse, which was largely disease treated in your series. Why exclude so many patients if you have confidence in the technique?

Dr Gillinov. I think now that we have looked at our results, you are right, we have confidence in the technique and are beginning to extend our indications. We will use axillary cannulation for the small femorals or for aortoiliac atherosclerosis. We haven't yet tackled reoperations with vigor, but we are looking at those.

The one thing, though, that is really off-putting to me with the robot is the person who has aortic insufficiency that is more than $1+$. I would still stay away from aortic insufficiency, because when you take the clamp off, if the ventricle distends, you could be in big trouble.

Dr Guy. Excellent. On the basis of the lessons learned from this large experience, where do you think robotic mitral valve surgery fits into the future of mitral valve intervention given the relative tsunami of catheter devices for the treatment of mitral valve disease that has set upon our shores?

Dr Gillinov. Yes, I see them when I look out at the sea. They are coming in; they are almost here. I think the robotic approach is here to stay because it offers the ability to do the same complete repair with all of the maneuvers you might use through a sternotomy but via a truly minimally invasive approach. Right now I don't see any single transcatheter repair device that will be able to replicate this. I think in your patients aged 50,60,70 years, or even 80 years, if that person has mitral valve prolapse, we want to do the best operation we can. So I think it is here for a good long while.

Dr S. Hasan (Karachi, Pakistan). Congratulations, Marc. A wonderful series and well presented. Is there a distinct advantage to using the robot over a minithoracotomy approach?

Dr Gillinov. They are almost the same operation, truthfully, and I think the robot is one way to do a nonsternotomy or sternal-sparing approach. I don't think there are any data to suggest one is necessarily better than the other, though.

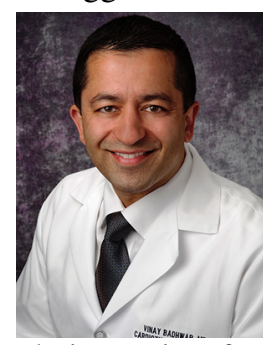

Dr V. Badhwar (Morgantown, WVa). I am interested in your decision to go from the Chitwood clamp to the EndoClamp back to the Chitwood clamp. As you know, there are several individuals who are practicing robotic surgery and are using the EndoClamp with great success. For someone who is contemplating going from the Chitwood as a standard to EndoClamp to do redos, what guidance can you provide us on how you made your decision on clamping technique?

Dr Gillinov. We use the Chitwood transthoracic clamp because it is $100 \%$ reliable; you always get occlusion of the aorta. With the EndoClamp, the balloon is placed transfemorally; it will occasionally migrate, sometimes you don't get good occlusion from the get-go, and then occasionally you will have trouble with cardioplegia delivery if the port that enables the cardioplegia to come out is against the wall. So it is kind of finicky, in addition to costing more.

That said, if you are going to do a redo, it offers distinct advantages, because you don't have to dissect out the aorta. But the Chitwood clamp is our go-to because it is easy and it is reliable.

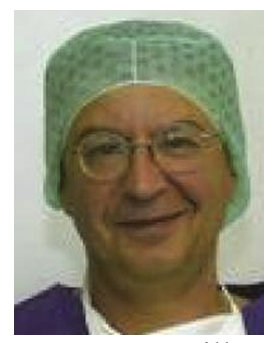

Dr D. Mazzitelli (Munich, Germany). Did you use the last generation of robotic from the beginning of this series, I mean with the fourth arm, the 3dimensional camera was used from the beginning in this series?

Dr Gillinov. In this series, we used the $\mathrm{Si}$ for most cases. We have a Xi on the way, so we will see how we do with that.

Dr Mazzitelli. I think this significantly helps to improve the results with the new generation.

Dr Gillinov. I think the $\mathrm{Xi}$ is wonderful. 


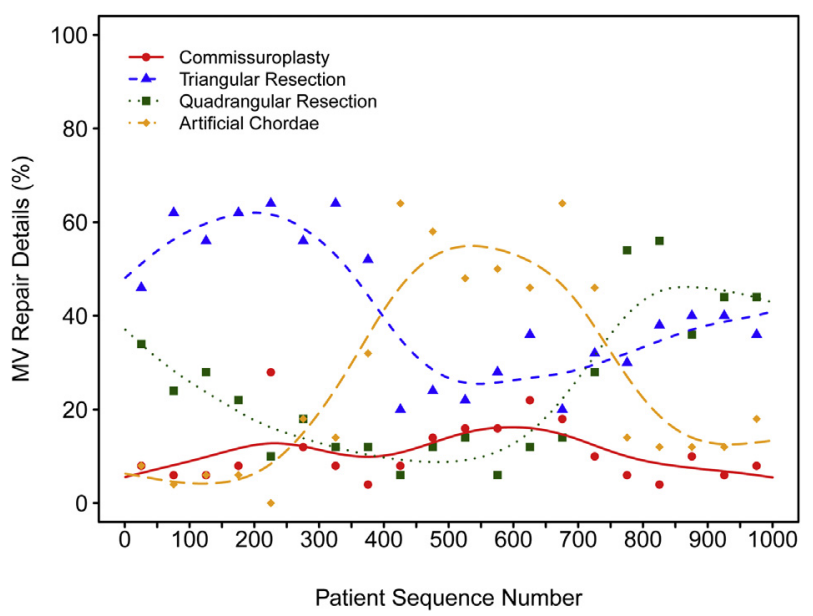

FIGURE E1. Examples of trends in mitral valve repair complexity. Lines represent the smoothing spline curve, and symbols represent the percentage for every 50 patients. $M V$, Mitral valve.

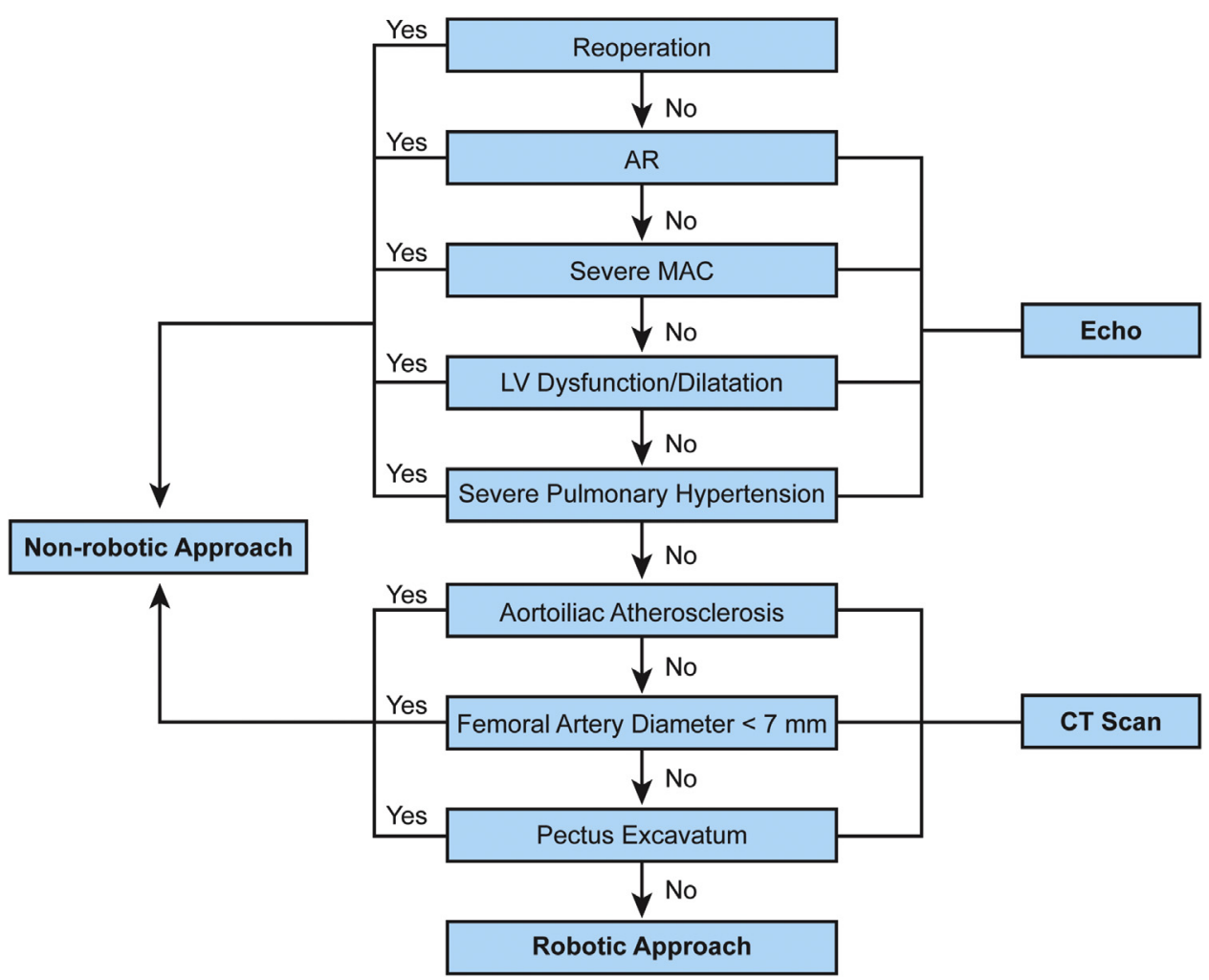

FIGURE E2. Algorithm to select candidates for robotically assisted mitral valve surgery. $A R$, Aortic regurgitation; $M A C$, mitral annular calcification; $L V$, left ventricular; $C T$, computed tomography. 
TABLE E1. Association of patient sequence number and in-hospital outcomes (each entry represents an independent analysis)

\begin{tabular}{|c|c|c|c|}
\hline Outcome & Unadjusted estimate + SE & Change & $P$ [trend] \\
\hline \multicolumn{4}{|l|}{ Binary variables* } \\
\hline Additional pump run & $3.5 \times 10^{-6} \pm 0.00036$ & - & $>.9$ \\
\hline Unsatisfactory repair & $-0.00028 \pm 0.00038$ & - & .5 \\
\hline Transfusion $\dagger$ & $-0.25 \pm 0.086$ & $\downarrow \ddagger$ & .003 \\
\hline Conversion to sternotomy & $-0.00035 \pm 0.00078$ & - & .7 \\
\hline Stroke & $-0.0013 \pm 0.00097$ & - & .2 \\
\hline New-onset atrial fibrillation & $0.00052 \pm 0.00028$ & - & .07 \\
\hline \multicolumn{4}{|l|}{ Continuous variables $\S$} \\
\hline $\begin{array}{l}\text { Preoperative left atrial } \\
\text { diameter }\end{array}$ & $-0.0000080 \pm 0.000096$ & - & .9 \\
\hline $\begin{array}{l}\text { Cardiopulmonary bypass } \\
\text { time } \dagger\end{array}$ & $-5.1 \pm 1.1$ & $\downarrow \ddagger$ & $<.0001$ \\
\hline Myocardial ischemic time $\dagger$ & $-7.7 \pm 0.82$ & $\downarrow \ddagger$ & $<.0001$ \\
\hline $\begin{array}{l}\text { Postoperative length of } \\
\text { stay } \dagger\end{array}$ & $-0.13 \pm 0.063$ & $\downarrow \neq$ & .04 \\
\hline $\begin{array}{l}\text { Intensive care unit length of } \\
\text { stay }\end{array}$ & $-0.0058 \pm 0.0029$ & $\downarrow \ddagger$ & .05 \\
\hline
\end{tabular}

TABLE E2. Predischarge echocardiography evaluation of patients

\begin{tabular}{lcc}
\hline \multicolumn{1}{c}{ Variable } & $\mathbf{n}^{*}$ & No. $(\%)$ or Mean \pm SD \\
\hline MR grade & 935 & $832(89)$ \\
None & & $83(8.9)$ \\
Mild & $18(1.9)$ \\
Moderate & $2(0.21)$ \\
$\quad$ Moderate to severe & \\
TR grade & 887 & $457(52)$ \\
None & & $301(34)$ \\
Mild & & $111(13)$ \\
Moderate & $14(1.6)$ \\
Moderate to severe & & $4(0.45)$ \\
Severe & & \\
AR grade & 685 & $615(90)$ \\
$\quad$ None & & $53(7.7)$ \\
Mild & & $16(0.3)$ \\
Moderate & & $53 \pm 7.0$ \\
$\quad$ Moderate to severe & \\
Left ventricular ejection & 965 & $34 \pm 7.7$ \\
fraction (\%) & & \\
Right ventricular systolic & 679 & \\
pressure (mm Hg) & & \\
\hline$S D$, Standard deviation; $M R$, mitral regurgitation; $T R$, tricuspid regurgitation; $A R$, \\
\hline
\end{tabular}

aortic regurgitation. *Patients with data available. 